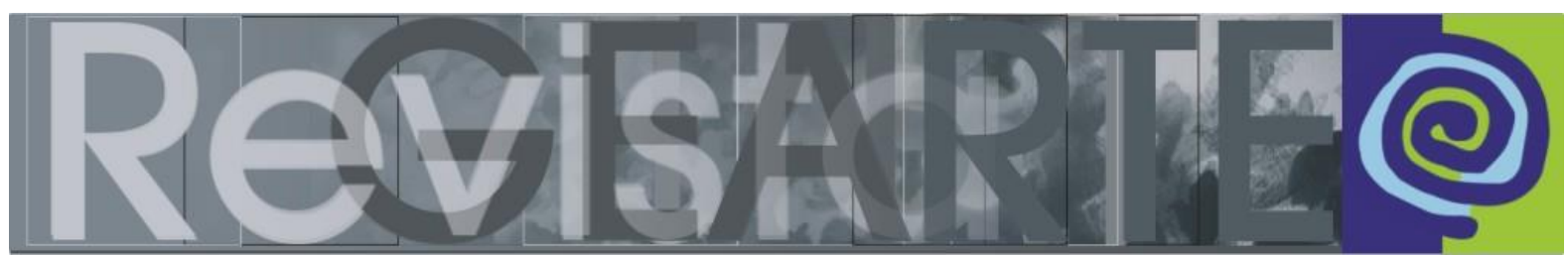

ISSN 2357-9854 | e-ISSN 2596-3198 (online)

\title{
Na escola, na cidade, no museu: fazer e pensar artes visuais na educação infantil
}

\author{
Luciana Esmeralda Ostetto \\ (Universidade Federal Fluminense - UFF, Niterói/RJ, Brasil)
}

\author{
Maria Isabel Melo \\ (Agrupamento de Escolas Manuel Ferreira Patrício - AEMFP, Évora, Portugal)
}

\begin{abstract}
RESUMO - Na escola, na cidade, no museu: fazer e pensar artes visuais na educação infantil - Ao refletir sobre as artes visuais na Educação Infantil, o artigo parte de uma concepção teórica e prática de arte como um processo contínuo e cotidiano - que envolve pesquisar, experimentar, explorar materiais, ideias e possibilidades, projetar, realizar —, para então questionar a pertinência da expressão "ensino de arte" no âmbito na Educação Infantil. As questões conceituais são articuladas à prática docente, por meio de retratos dos fazeres e saberes construídos por um grupo de miúdos de 3 a 6 anos e sua educadora, em uma instituição de educação pré-escolar pública de Évora - Portugal. Tematiza a importância dos materiais, dos espaços e da experimentação que desencadeiam e/ou intensificam o pensamento criativo e a contribuição de visitas a museus e de passeios na cidade como oportunidades para aprender a observar, a refinar o olhar e potencializar os processos criativos e simbólicos das crianças.
\end{abstract}

PALAVRAS-CHAVE

Arte e Educação Infantil. Artes Visuais. Linguagens Expressivas. Educação Estética.

RESUMEN - En la escuela, en la ciudad, en el museo: hacer y pensar las artes visuales en la educación infantil - Al reflexionar sobre las artes visuales en la Educación Infantil, el artículo parte de una concepción teórica y práctica de arte como un proceso continuo y cotidiano - que involucra investigar, experimentar, explorar materiales, ideas y posibilidades, proyectar, realizar -, para entonces cuestionar la adecuación de la expresión "enseñanza de arte" en el ámbito de la educación infantil. Los aspectos conceptuales se articulan a la práctica docente, a través de retratos de actividades y conocimientos construido por un grupo de niños de 3-6 años y su maestra en una institución de educación preescolar pública de Évora - Portugal. Discute la importancia de los materiales, de los espacios y de la experimentación que pueden desencadenar y/o intensificar el pensamiento creativo; reflexiona sobre la contribución de visitas a museos y de paseos en la ciudad como oportunidades para aprender a observar, a refinar la mirada y potenciar los procesos creativos y simbólicos de los niños.

PALABRAS CLAVE

Arte y Educación Infantil. Artes Visuales. Lenguajes Expresivos. Educación Estética.

\section{Arte, crianças, educação infantil: os conceitos definem caminhos}

Quando se trabalha com a primeira infância, arte não é algo que ocorra isoladamente. Ela engloba: controle corporal, coordenação, equilíbrio, motricidade, sentir, ver, ouvir, pensar, falar, ter segurança. (HOLM, 2007, p. 12). 


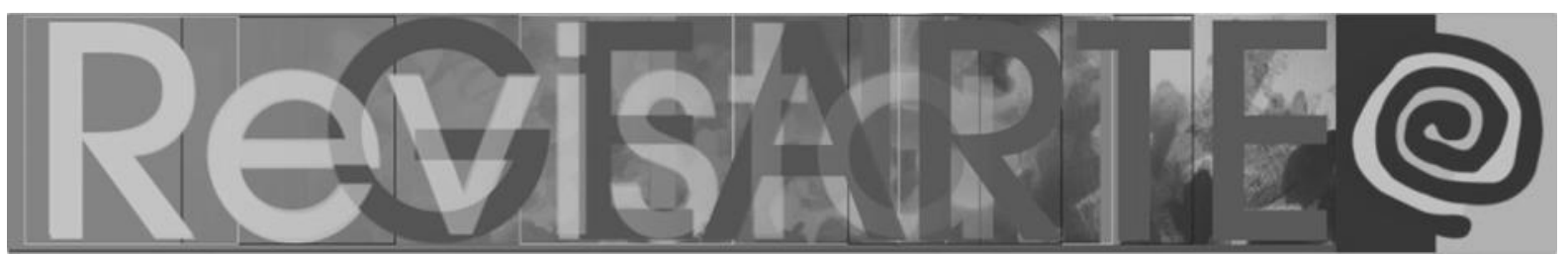

Ao pretendermos falar de artes visuais na Educação Infantil, trazemos ao diálogo a artista contemporânea Anna Marie Holm (1951-2015), que (re)desenhou concepções e práticas no território de confluência constituído pelos campos da arte, da infância e da educação. As experiências desenvolvidas na oficina de arte para crianças que mantinha na Dinamarca, que podem ser conhecidas por meio das notas tomadas em diários, posteriormente publicados, contam de produtos, processos e sujeitos-produtores envolvidos em propostas singulares que na oficina tinham lugar. As observações que compartilha revelam não apenas o olhar sensivelmente cuidadoso para o os fazeres e saberes das crianças, reparando em seu ser poético, mas dão a conhecer um trabalho profundamente enraizado na confiança que nutre pelas crianças e no respeito as suas múltiplas linguagens.

O conteúdo articulado em suas notas e reflexões corrobora, no âmbito da educação da infância, o que está posto no âmbito mais geral da vida: arte é totalidade, envolve múltiplos aspectos, perpassa variadas dimensões do humano, não se reduz ao produto de um fazer criativo. Nele reconhecemos, também, elementos que reafirmam as crianças como produtoras de cultura, que vivem, apreendem e expressam o mundo com todos os sentidos; sujeitos que, nas interações estabelecidas com o ambiente sócio-histórico-cultural, na relação com os objetos que experimentam, em movimentos curiosos e intensos de ouvir, falar, ver, mexer/remexer, juntar/separar, fazer/desfazer, montar/desmontar, entre realidade e imaginação, entre limites e possibilidades, vão sendo afetados, vão conhecendo e aprendendo a expressar o mundo de diferentes maneiras.

De partida, são esses princípios que evocamos para pensar as artes visuais na Educação Infantil, reafirmando que experimentar materialidades, pesquisar características físicas e simbólicas dos materiais enquanto os manipula, pode fertilizar processos de criação que, suscitados por hipóteses formuladas na ação com/sobre a matéria, ampliam possibilidades expressivas, alargando, por sua vez, o conhecimento do mundo. Nesse processo criador, a criança envolve-se de corpo inteiro, sentindo e pensando. 


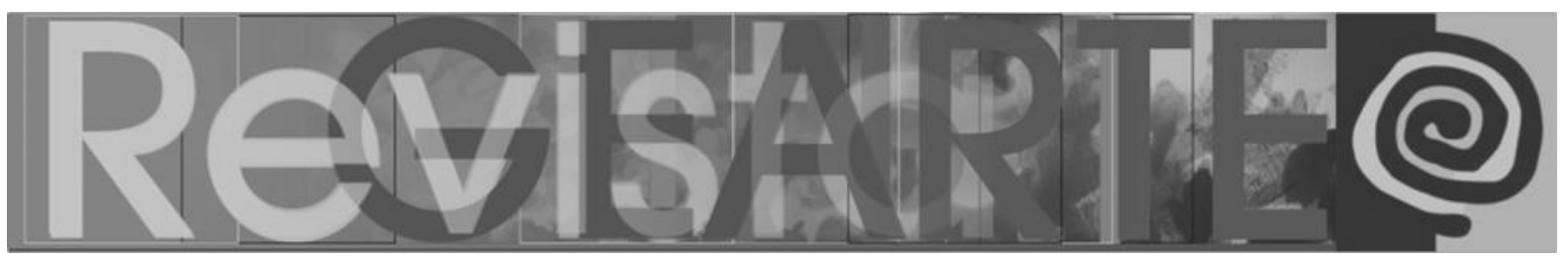

Tal perspectiva entrelaça uma concepção teórica e prática de arte como um processo contínuo e cotidiano, que envolve pesquisar - experimentar, explorar materiais, ideias e possibilidades, projetar, realizar (HOLM, 2004; OSTETTO, 2011). Por isso, propostas com as artes visuais vão além de um fazer isolado e rompem aquela perspectiva de desenvolvimento de atividades, com começo, meio e fim definidos.

Como pode o adulto saber onde termina o processo artístico? Ou conhecer o caminho de antemão e ter a situação sob controle? Se não entendermos que o processo artístico é aberto, então aquilo com o qual estamos trabalhando não é arte. (HOLM, 2004, p. 88).

Concordamos com Judith Burton (2016, p. VI): "[...] um dos maiores feitos da cultura humana, a criação artística, começa, assim, profundamente enraizada nas atividades exploratórias das crianças em idade de creche e de jardim de infância". Todavia, é fato que em direção contrária tem seguido a prática: os trabalhinhos ou as cópias refinadas de obras de artistas, mascaradas de releitura, num enquadramento de atividades que excluem a exploração ativa das crianças, ainda são realidade.

Essas questões nos levam à reflexão sobre a pertinência da denominação "ensino de arte", no âmbito da Educação Infantil. Para desenvolver propostas educativas no campo da arte, com crianças de zero a seis anos, na primeira etapa da Educação Básica, valeriam princípios e práticas de outras etapas da escolaridade, historicamente inscritas como ensino de arte?

Enfrentando a discussão, tecemos diálogos com a experiência italiana de Reggio Emília, na qual identificamos a perspectiva de um trabalho que considera central não o ensino de arte, mas o que chamam de linguagens expressivas. Envolvendo conhecimentos da arte e da cultura, num campo ampliado das linguagens simbólicas, poéticas, expressivas, fala-se de educação estética, onde as linguagens visuais, e outras, estão presentes "como a construção de pensamentos e sentimentos dentro de uma educação holística" (VECCHI, 1999, p. 129). 


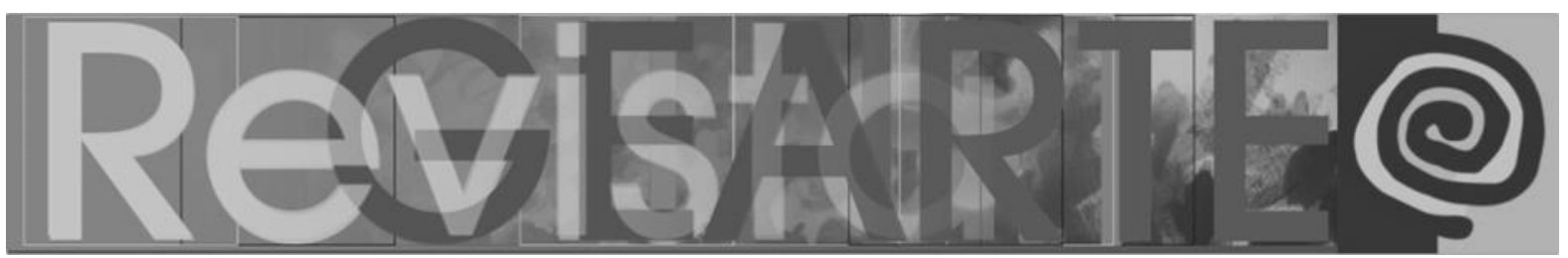

As linguagens expressivas, como linguagens poéticas, "[...] são formas de expressão marcadamente caracterizadas pelos aspectos expressivo ou estético, como a música, o canto, a dança ou a fotografia" (VECCHI, 2013, p. 63). Contemplálas na Educação Infantil pressupõe a organização de tempos e espaços, disponibilização de materiais, que oportunizem às crianças

[...] interrogar e indagar o mundo, construindo pontos e relações entre experiências e linguagens diversas, para tomar em estreita relação os processos cognitivos e aqueles expressivos, em contínuo diálogo com uma pedagogia que procura trabalhar sobre as conexões e não sobre as separações dos saberes (VECCHI, 2007, p. 138-139).

Um trabalho que, no diálogo com o campo de conhecimento arte, em suas diversas entradas conceituais, práticas e simbólicas, é um processo cotidiano, contínuo, que não pode se restringir a uma aula de arte, a um plano de ensino de artes visuais ou à utilização de materiais marcadamente artísticos.

$\mathrm{Na}$ intenção de ampliar as referências experienciais e conceituais que vimos enunciando, a seguir puxamos mais um fio para nosso tecido reflexivo: o pensar e o fazer artes visuais na Educação Infantil são amplificados no diálogo com o trabalho de uma educadora de infância portuguesa, coautora do presente artigo.

\section{Itinerários docentes: modos de pensar e de fazer artes visuais na educação infantil}

Nesse item, as narrativas que tematizam a presença da arte no projeto pedagógico desenvolvido com um grupo de 20 crianças de 3 a 6 anos e sua educadora, em uma instituição de educação pré-escolar pública de Évora, Portugal, abrem-se como um convite à continuidade reflexiva. Ainda que, quando julgamos conveniente, a voz da educadora seja entremeada com referências bibliográficas, não se pretende explicar ou discutir o conteúdo narrativo, pois os retratos falam por si. Intencionamos que o leitor trace o seu itinerário, (re)componha sentidos além do texto, (re)velando outros retratos. 


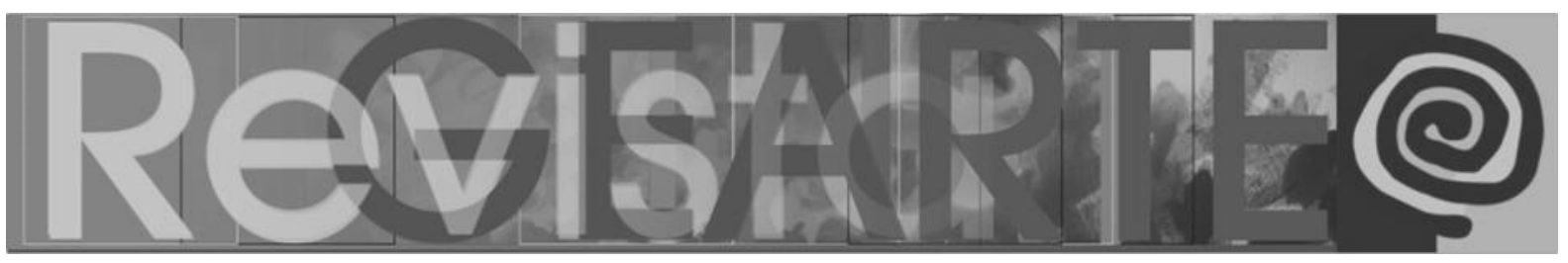

\subsection{Uma proposta para potenciar o desenho}

Acompanhando as crianças, percebi que desenhavam pouco; os temas, de certo modo estereotipados, se repetiam: uma casinha, uma árvore, um menino, a nuvem, o sol. Então conversava sobre o que tinham desenhado, refletia com eles, fazendo-os pensar sobre o que estava desenhado; depois propunha, com o intuito de contribuir com os seus processos expressivos: se o desenho era de uma casa, por exemplo, propunha que olhassem a casa que estava ao lado da sala, questionava como seria ou como poderiam desenhá-la. Tem flores? Como são elas? E as árvores ao redor? As perguntas ajudavam a ampliar seus olhares e provocavam o pensar sobre 0 desenho que gostariam de realizar.

Para além desse exercício-diálogo, que já era comum entre nós, trouxe para o grupo uma proposta de provocação: criar uma caixinha de coisas que poderiam ser desenhadas, que deixaríamos numa área da sala especialmente organizada para desenhar. E assim fizemos, na caixa colocávamos coisas que eu trazia e que eles traziam de casa, ou coisas que encontrávamos em nossas saídas: inúmeras vezes eles encontravam algo na rua e diziam - Olha, isso acho que serve pra desenhar! E logo apanhavam para levar à sala, para compor a caixa de desenho. Ao longo de um tempo, dentro da caixa ficaram disponíveis diversos elementos e, quando queriam, podiam ir lá desenhar escolhendo dentre os elementos existentes. Foi um processo muito mobilizador. Com imensa participação, eles iam percebendo que podíamos desenhar o que se vê, quando estamos olhando; e podíamos desenhar o que temos na memória.

Esse processo contribuiu para o exercício de olhar, convidava-os a olharem bem para as coisas e pensar no que/como poderiam desenhar aquilo que estavam a ver. (MELO, 2009, p. 2).

No processo de representação gráfica, a observação é um ponto muito importante. Olhar, observar, é aprendizagem e, no trabalho com artes visuais, é um foco de atuação docente essencial. O exercício de observação e refinamento dos sentidos, é enriquecido com as saídas para passeios à cidade. São imensas oportunidades para ampliar olhares e fortalecer aprendizagens que podem contribuir para o exercício de representação gráfica, apurando os traços e a expressividade no desenho.

Quando eu os levo à cidade, eles também são indagados:

- O que estamos a ver aí?

- Ah, eu estou a ver umas escadas.

- E as escadas vão dar aonde?

- Vão dar a uma porta.

- Então: temos as escadas, a porta... (MELO, 2019, p. 2) 


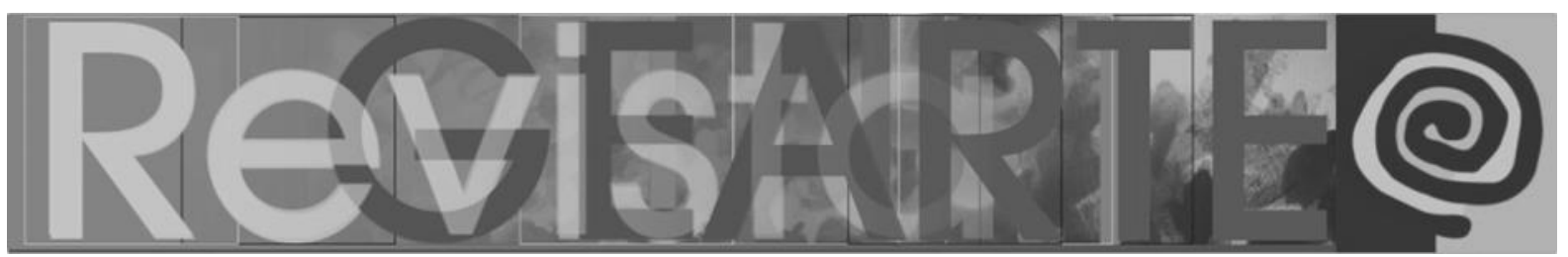

Em uma saída com as crianças pela cidade, com a proposta de desenhar o que se encontra pelo caminho, entre paisagens e construções, no ambiente próximo e distante, é importante focar, e para tanto é preciso ajudar meninos e meninas a olhar, a decidir o que vão olhar, o que querem ver mais, o que vão desenhar. Elas precisam de foco, pois é fácil dispersar o olhar; diante de tantos elementos, olham para tudo e não olham nada. É difícil escolher: o que é que eu vejo? Tanta coisa! Precisamos ajudá-los a olhar, pois compreendemos que, para ampliar as possibilidades do desenho, é importante reparar nos detalhes, pensar no que estão a ver e no que querem colocar no papel. O professor cumpre um importante papel de apoiar "as crianças nas suas descobertas, umas vezes dando-lhes a conhecer pensamentos e ideias, outras simplesmente não atrapalhando os seus pensamentos e ideias." (CABRAL, 2016, p. 3). Algumas pequenas histórias que falam dessa questão, estão a seguir.

\begin{abstract}
Além da Sé.
Um dia saímos para desenhar a Sé de Évora. Cada qual fez seu desenho, colocou seu nome. Na chegada à escola, cada criança mostrou o que desenhou. Um menino mostrou o seu e havia algo nele que eu não percebi. E perguntei: - O que é isso? - Ó Isabel, então não viste a mota estacionada na frente da Sé? Portanto, ele desenhou perfeitamente a igreja e a mota estacionada a sua frente, como fazendo parte daquela paisagem, capturada pelo seu olhar. Então rimo-nos todos, porque estou farta de dizer que eles precisam ver tudo. E lá estava, o menino vendo aquele detalhe, a mota, que ninguém mais tinha visto!
\end{abstract}

\title{
Bolas?
}

Um outro menino trazia a folha com bolas e bolinhas, círculos, muitos, desenhados por toda a folha. Onde terá aquele miúdo visto tantas bolas? Ora, eram as pedras... do caminho, do chão, dos monumentos. É interessante pensar no que marcou naquele menino, que era um dos mais novos do grupo. $\mathrm{O}$ que ele observou e registrou? Um detalhe, as pedras! Quando me dei conta, achei fantástico, pois se estávamos sentados ao chão: pedras; olhando o templo romano: pedras. As pedras impressionaram o olhar no menino e os círculos que produziu estavam cheios de significados com relação ao contexto.

\section{Reconhecer para desenhar.}

Quando olhamos a cidade lá de cima do Jardim de Diana, olhamos para aquele casario lá embaixo, alguns meninos disseram: - Eu não consigo desenhar, é muita coisa! Foi então que me dei conta, eram realmente imensas coisas, difícil escolher. Entre dificuldades de alguns, houve uma menina que disse: - Olha o meu bairro, eu vou desenhar o meu bairro! No meio daquela paisagem cheia de casas, ela identificou onde morava e se colocou a desenhar o bairro que conhecia, por onde ia e vinha todos os dias. 


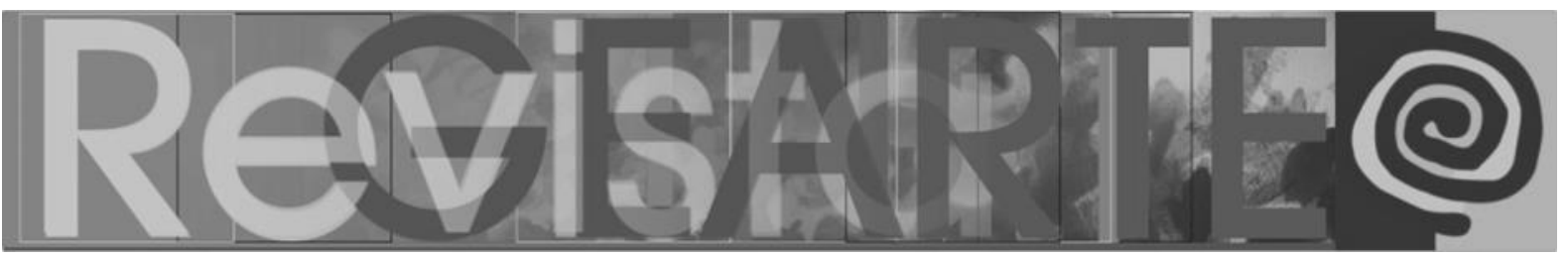

Por ter intimidade com aquela paisagem, poderíamos supor que seu olhar tantas vezes percorrera a região, talvez mediado pelos adultos, pela família, seu olhar fixou detalhes e, de longe, no conjunto à sua frente, pudera reconhecer seus elementos. (MELO, 2019, p. 4)

Figura 1 - Crianças desenhando (Praça do Giraldo) - Évora

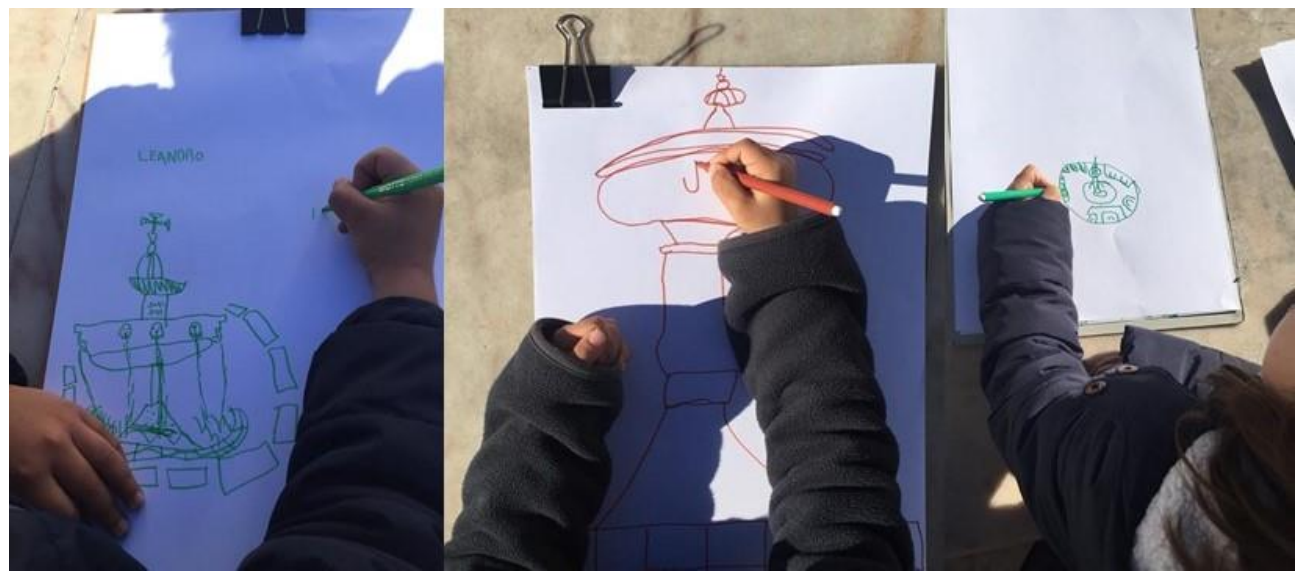

Fonte: Arquivo de Maria Isabel Melo.

Figura 2 - Crianças desenhando (Igreja de São Francisco) - Évora

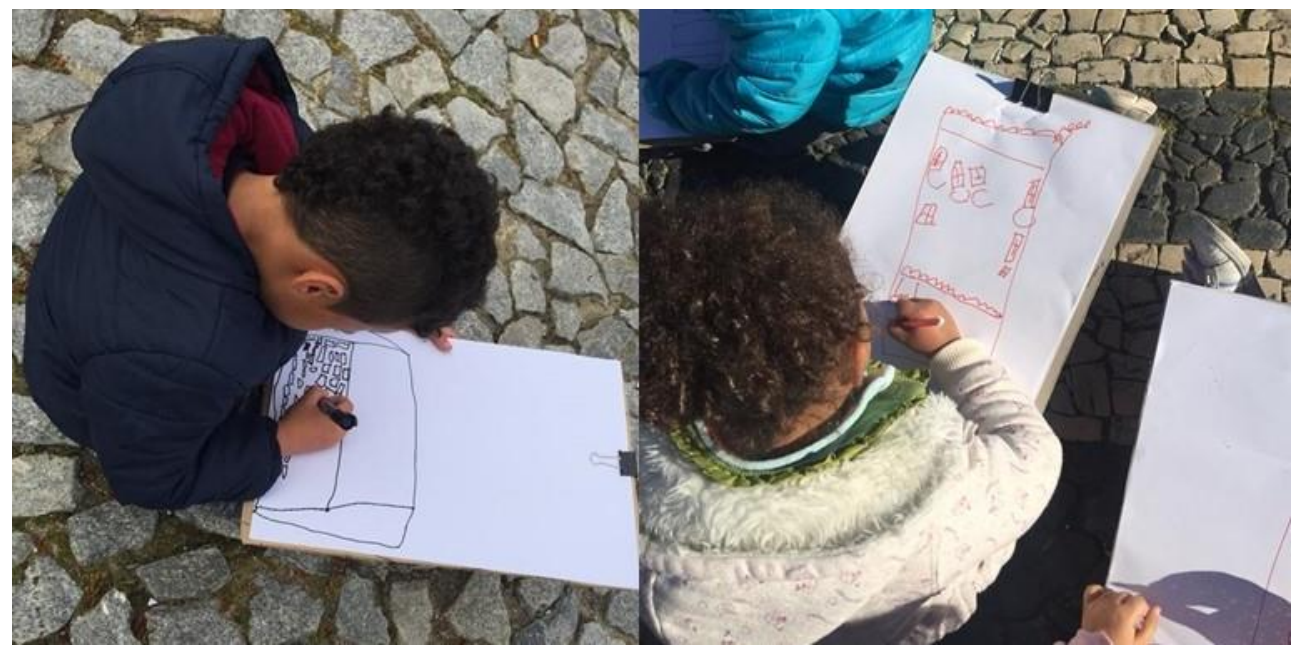

Fonte: Arquivo de Maria Isabel Melo. 


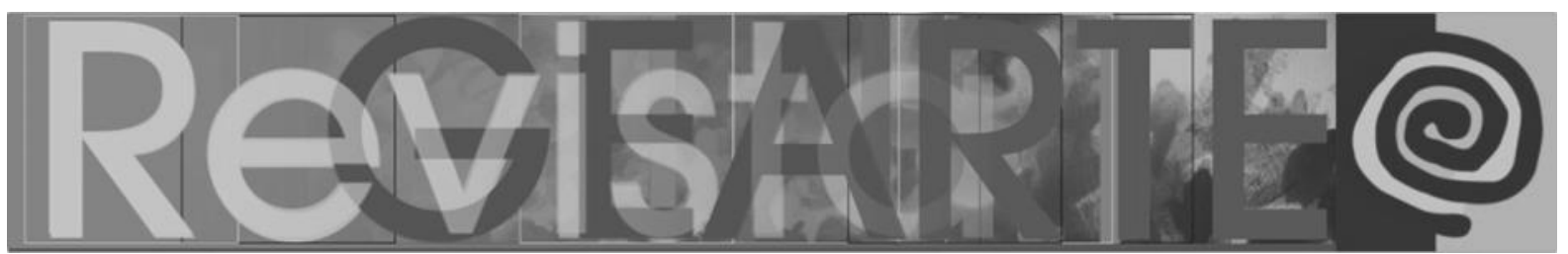

Figura 3 - Crianças desenhando (Templo Romano) - Évora

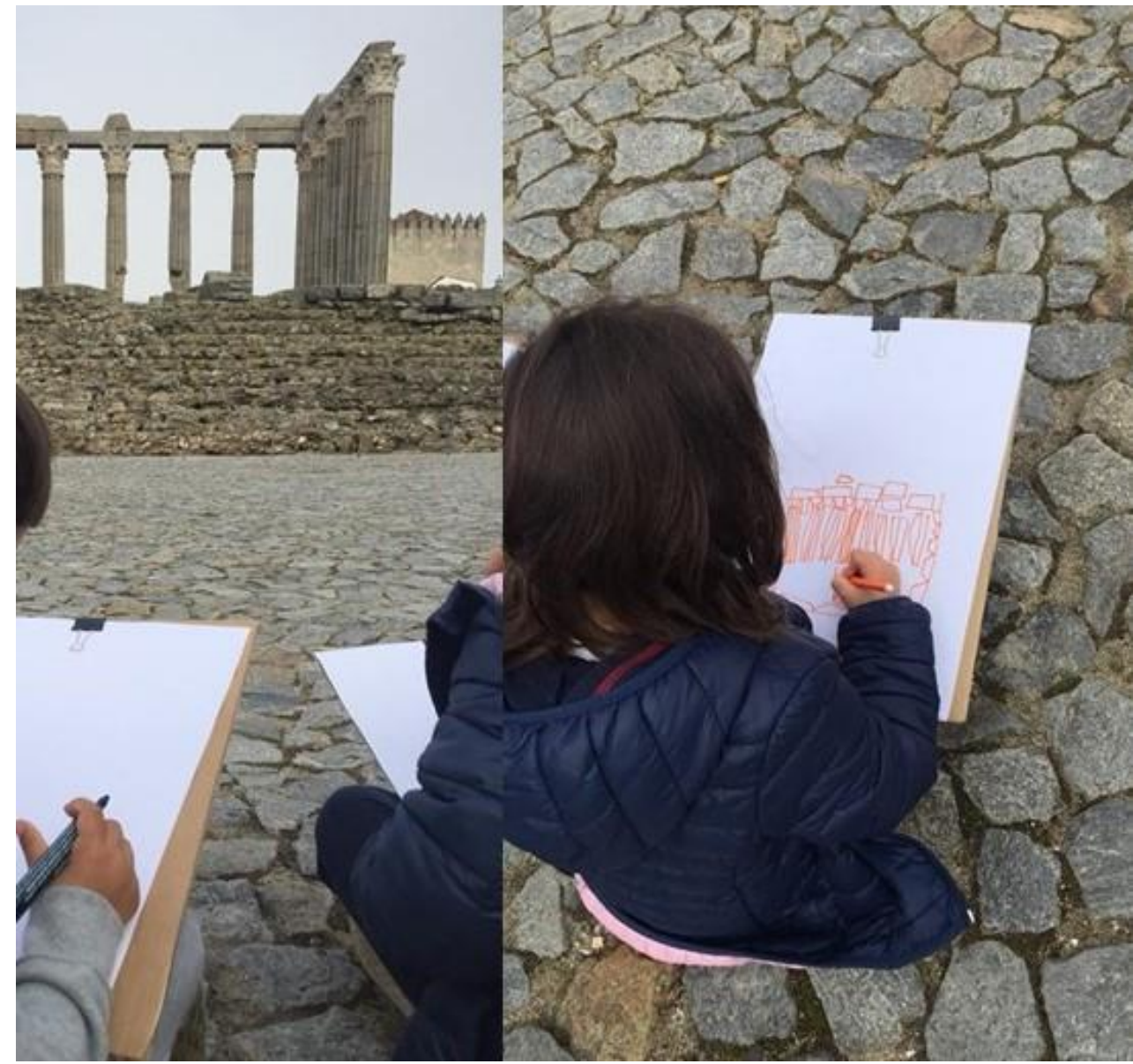

Fonte: Arquivo de Maria Isabel Melo.

Se ajudar a olhar e focar os elementos que se quer desenhar é importante, quais são os apetrechos utilizados em uma saída à cidade, quando o projeto é desenhar elementos e paisagens vistas? É muito funcional utilizar pranchetas para apoio. É um material caro? Mas é possível fazê-las em papel cartão muito grosso, cartão/papelão de caixa e, com uma mola para prender o papel, está feito um bom suporte para apoiar os processos de observar/desenhar. É bom disponibilizar uma folha maior, A3, para esse exercício de desenho. Para o traçado, canetas hidrocor, geralmente de uma cor só, são bem empregadas. A experiência tem revelado que "as crianças se dedicam mais à forma, se concentram mais no traço, quando têm à disposição uma cor apenas" (MELO, 2019, p. 4). 


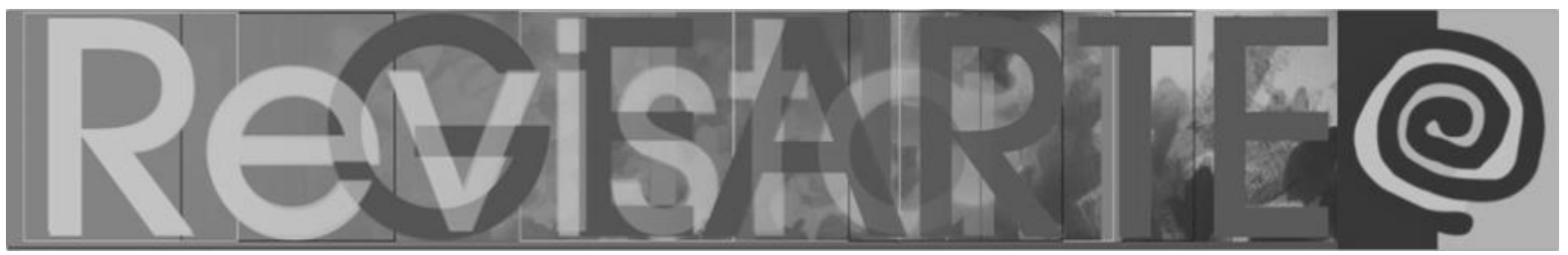

1.2. Sobre materiais e espaços: a experimentação desencadeia o pensamento criativo

[...] a produção artística contribui para aprendizagens essenciais, que incluem os muitos e diversificados modos como os materiais - tintas, lápis de cera, madeira e barro - se tornam as vozes através das quais e com as quais se constroem ideias fundamentais, observações, experiências, significados. (BURTON, 2016, p. VI).

A relação com os materiais disponíveis no cotidiano, o contato íntimo com diversas materialidades e suas propriedades, entre aromas, texturas, formas, cores, sons, engendra processos de apropriação e desenvolvimento de diferentes linguagens expressivas, pelos quais/com os quais as crianças vão constituindo redes de significados, esboçando narrativas pessoais, em composições próprias, autorais. É pela experimentação que o pensamento criativo é desencadeado e pode se desenvolver, pois enquanto manipulam, juntam e transformam materiais, produzem ideias, sentimentos e significados. Ao experimentar, seguindo por caminhos desconhecidos, "[...] a criança desenvolve sua sensibilidade e adquire uma consciência maior de todos os sentidos" (HOLM, 2007, p.12).

Explorar e aprender sobre as qualidades dos materiais é caminho fecundo, e imprescindível, para o trabalho com artes visuais na Educação Infantil, para intensificar processos expressivos e de produções artísticas. Porém, não basta ter os materiais, sofisticados ou não, ao dispor das crianças; é fundamental a presença acolhedora de adultos que se envolvam

[...] nas explorações e aprendizagens das crianças, escutando-as e dialogando com elas, encorajando-as a desenvolverem-se e a apropriaremse dos seus pensamentos à medida que encontram maneiras de se exprimir através de materiais artísticos. (BURTON, 2016, p. VI).

Se os materiais são recursos que potenciam ou limitam a experiência de criação, precisam ser analisados, selecionados e organizados, atentando-se às possibilidades que oferecem, segundo suas qualidades - lisos e ásperos, secos e molhados, duros e moles, grandes e pequenos, transparentes e opacos etc. Como observado pela artista: 


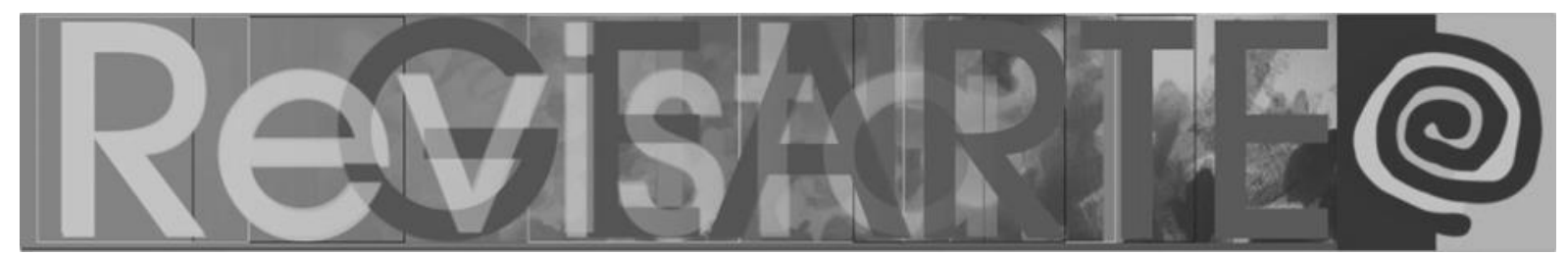

[...] quando as crianças têm a oportunidade de escolher materiais diferentes, elas o fazem. Elas encontram o que é mais adequado para elas. Fazem, produzem imagens, pintando e montando instalações a partir de materiais que os adultos nem sonhariam em juntar. De repente, fantásticos espaços e trabalhos vão surgindo. (HOLM, 2004, p. 86).

De outra forma, os materiais, por si só, não garantem experimentações criativas; é necessário pensar em sua disposição no espaço, de modo a compor ambientes que contribuam para explorações e pesquisas, que gerem experiências intensas de ativação dos sentidos. Disponibilizar papéis de tamanhos e tipos variados, grandes, pequenos, grossos, finos, opacos, transparentes, que são restos/retalhos, que podem até ter impressão de um lado, servem bem para recortar, desenhar, fazer colagem, pintar por cima. Os papéis especiais, como cartolina, papel de aquarela, papel cenário, contribuem para a diversidade de projetos a que as crianças poderão se envolver. Papéis que em suas formas, dispostos em quadrados, círculos, retângulos, grandes ou pequeninos, já provocam a imaginação, convidam à criação.

Figura 4 - Crachá em papel desenhado

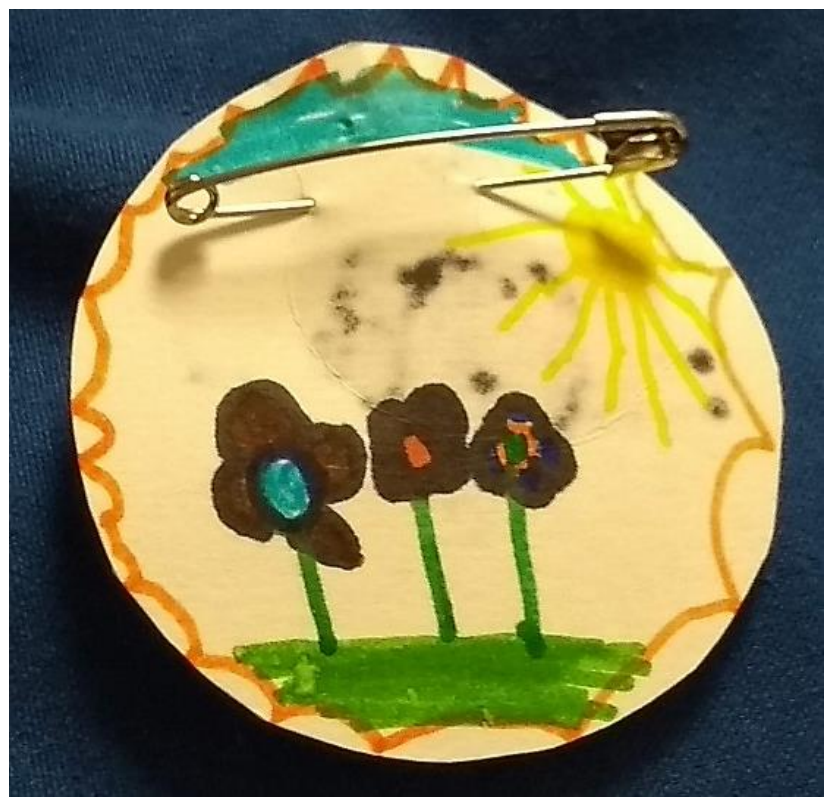

Fonte: Arquivo de Luciana Esmeralda Ostetto.

Olha isso! É de um menino que agora encontrou esses círculos de papelão, que estão na sala, na área em que temos os papéis.

Provavelmente ele já os tinha visto, porque estão disponíveis e acessíveis no sítio onde estão vários papéis, de diversos tipos - grandes, pequenos, grossos, finos, opacos, transparentes, brancos, coloridos, recortados em 


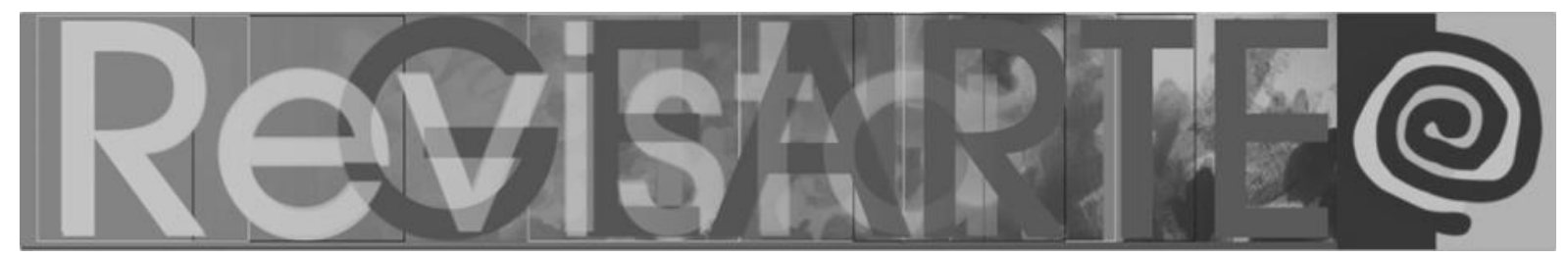

formas diversas... Parece que agora ele descobriu uma maneira de utilizar o círculo, e começou a fazer esses crachás, para todos; desenha-os e tem oferecido a todos os meninos (Fez muitos homens-aranhas, mas para mim ofereceu-me essas flores). Entendo que aqui ele se apoderou da forma: esses círculos de papelão, ele achou que era próprio, que servia, para fazer crachás. (MELO, 2019, p. 5).

Para que o menino chegasse à proposição de um crachá circular, utilizando a superfície com suas criações de desenhos coloridos, foi imprescindível que o material estivesse acessível, organizado de modo convidativo à experimentação, à manipulação, à composição autoral. Hoje sabemos que o espaço é um elemento do currículo, é constitutivo das aprendizagens, pois "Tudo o que cerca as pessoas na escola e o que usam - os objetos, os materiais, as estruturas - [são] elementos que condicionam e são condicionados pelas ações dos indivíduos que agem nela." (GANDINI, 1999, p.157). A maneira como os educadores organizam o espaço físico onde colocam os objetos e materiais (ao alcance das crianças ou no alto), que móveis dispõem e como os configuram (tudo encostado na parede ou formando pequenos recantos), que objetos disponibilizam (almofadas, mesas, cadeiras, brinquedos, áreas com materiais específicos para manipulação, exploração, criação, expressão), revelam concepções e expectativas quanto ao desenvolvimento infantil.

A forma como um espaço é organizado pode potencializar ou restringir interações, elemento central de desenvolvimento e aprendizagem na infância. No caso da ampliação das linguagens expressivas, por exemplo no campo das artes visuais, o papel do professor é decisivo quanto às concepções que definem suas escolhas para a organização espacial.

\footnotetext{
Para pintura, eu não uso cavaletes individuais. Na sala temos um painel para pinturas na parede; é pequeno, mas é o que temos... Acho que é mais produtivo, potencializa a aprendizagem, a troca, quando estão lado a lado. Eles têm que estar a ver-se uns aos outros, para se contaminarem. Eles também podem pintar à mesa ou num sítio que escolherem, lá fora, onde temos duas mesas grandes. (MELO, 2019, p. 5).
}

O espaço físico é um elemento que atua na constituição do pensamento (RINALDI, 2013), pois os arranjos de um ambiente, com a presença ou a ausência de diferentes materiais, imagens, cheiros, sons, por exemplo, direcionam e educam todos 


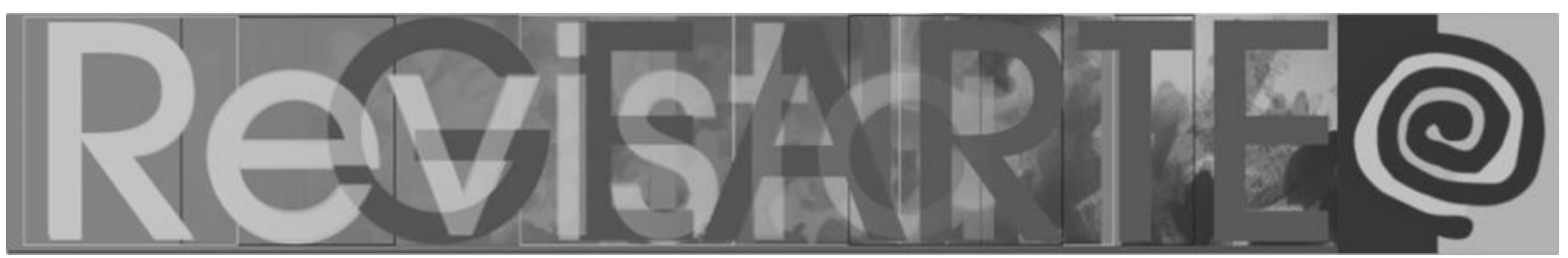

os sentidos. Nesse contexto, ao falarmos de artes visuais na educação infantil, há que se destacar um importante aspecto, tantas vezes desconsiderado: a composição estética de um espaço educacional, a começar pelos repertórios visuais, disponibilizados nas paredes. Além de atuarem na formação do gosto, os elementos/objetos que compõem um ambiente, das imagens aos objetos que o enfeitam, oferecem referenciais para o repertório imagético e o pensamento das crianças, são textos visuais, impregnados de significados (CUNHA, 2005).

Cuidar da estética dos espaços é parte do conteúdo de arte, no campo ampliado da formação estética, e habitar o espaço com as produções das crianças é de suma importância, pois contribui para o fortalecimento da identidade individual e coletiva: os elementos dispostos na sala oferecem às crianças a possibilidade de se reconhecerem como autoras e como pertencentes àquele grupo. Mas o famigerado "varal de atividades" pode ser superado com outras práticas e modalidades de exposição, surgidas muitas vezes de um problema, de uma limitação imposta pelo próprio espaço físico.

\footnotetext{
Na época dos incêndios de Pedrógão, aqui em Portugal, que destruiu muita coisa, à volta das conversas sobre os incêndios, que viam na televisão, que ouviam nas notícias e nos comentários dos adultos/famílias, fomos fazendo árvores: com galhos de árvores que recolhiam na rua e traziam, com barro, com cartão/papelão. Eles desenhavam, recortavam, montavam diferentes árvores. Fizemos tantas árvores! Ao final, tínhamos ali uma floresta, mas não tínhamos onde deixar aquelas árvores todas, belíssimas, que fizeram... Os meninos não queriam simplesmente guardar o que tinham feito. Queriam expor, mostrar para todos. Então... colocamos nas paredes da casa de banho, sobrepondo-as em painel. Aquele espaço inesperado se transformou em uma floresta! Diante da destruição, surgiu um trabalho de reconstrução, como se fosse um apelo. E colocar as árvores daquela maneira inusitada, na casa de banho, foi fantástica! As crianças chamavam os pais para irem ver, permitiu muitas interações e trocas (MELO, 2019, p. 6).
}

Quando o princípio estético move a proposta pedagógica, quando o educador articula fazeres artísticos com os sentidos da vida e com a essencialidade da beleza em todos os lugares, para além de uma atividade ou trabalhinho, cabe bem até o banheiro para acolher as produções e histórias dos meninos. 


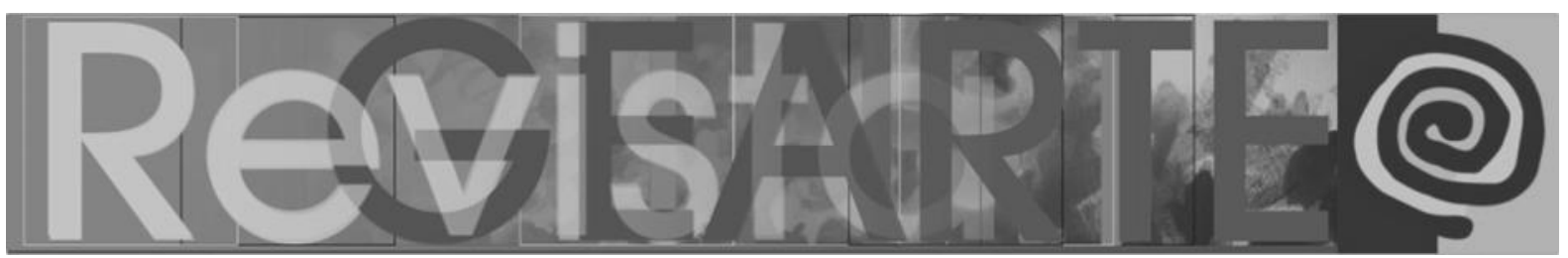

1.3. Visitar museus: despertar desejos e buscas, alimentar experiências estéticas

Assim como qualquer contemplador, diante da obra de arte a criança faz perguntas, deseja saber. Na busca por significar o que vê, aciona todos os seus sentidos, conhecimentos e experiências: "Cada passeio, cada visita, cada experiência suscita no contemplador sensações e indagações únicas: desperta desejos, abre portas para novas buscas..." (LEITE, 2005, p. 46). Promover expedições e passeios ao encontro da cidade, da arte e das produções culturais, é uma importante ação do trabalho com as artes visuais na educação infantil.

A frequentação a museus é canal para o desenvolvimento da educação estética, da educação do olhar, da ampliação de referências para percepções e sensibilidades. O contato com as obras no museu, permitem "[...] melhor visibilidade às cores, formas e técnicas utilizadas, interferindo também na relação do espectador com as dimensões das pinturas, dos desenhos ou fotografias e, no caso das obras tridimensionais, com o volume e seu entorno" (GANZER, 2005, p. 86).

As visitas não precisam estar associadas a um conteúdo de outra área, que se queira aprofundar ou relacionar, nem tampouco que seja realizada apenas em grandes exposições ou seguindo as propostas do serviço educativo disponibilizado pelos museus.

Normalmente eu levo-os ao museu depois de visitar a exposição. Se considerar interessante, eu levo-os. A exposição pode ter relação com o que estamos desenvolvendo em algum projeto, ou não. Se pretendo provocar outras coisas e produções, provocar o conhecimento das esculturas, por exemplo, eu levo-os. Mas sempre depois de eu ter visto a exposição... e de ter gostado dela.

Na visita recente, à exposição do João Cutileiro no Museu de Évora, como eu gosto muito do trabalho dele, conheço muito a sua obra para além da exposição, eu mesma orientei a visita. Falando um pouco sobre ele, sobre os tipos das esculturas, dos materiais que ele utilizava, as pedras. Surpreendime que muitos reconheceram a escultura de Dom Sebastião, porque muitos já foram ao Algarve e ela está lá. Na volta da visita, sempre nos reunimos para conversar sobre o que viram, sobre o que mais gostaram. No dia da visita à exposição do João Cutileiro, fotografamos as obras. Quando chegamos à sala, conversamos utilizando também as fotografias, o que ajudava a lembrar e a explorar mais os detalhes. Então fizemos o projeto de construir esculturas, escolhendo cada um o material que queria usar, não só o mesmo utilizado pelo artista, a pedra, como outros. (MELO, 2019, p. 6).

OSTETTO, Luciana Esmeralda; MELO, Maria Isabel. Na escola, na cidade, 509

no museu: fazer e pensar artes visuais na educação infantil.

Revista GEARTE, Porto Alegre, v. 6, n. 3, p. 497-513, set./dez. 2019.

Disponível em: http://seer.ufrgs.br/gearte 


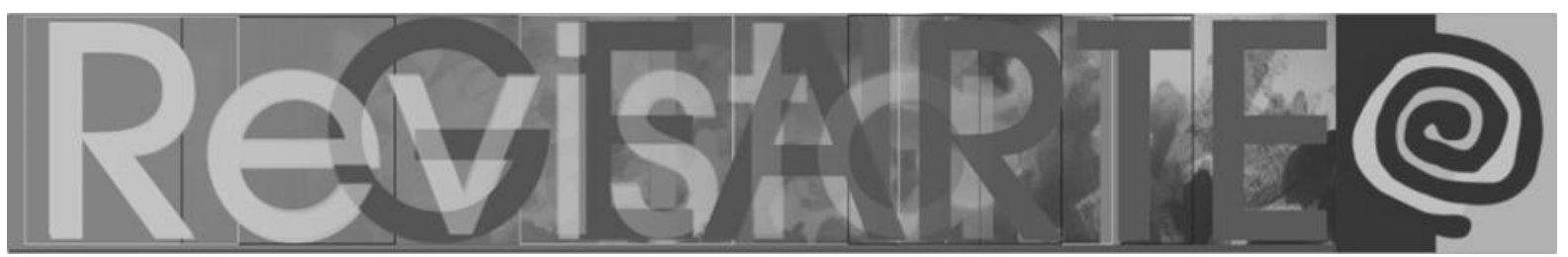

Figura 5 - Escultura com madeira e elemento de papel

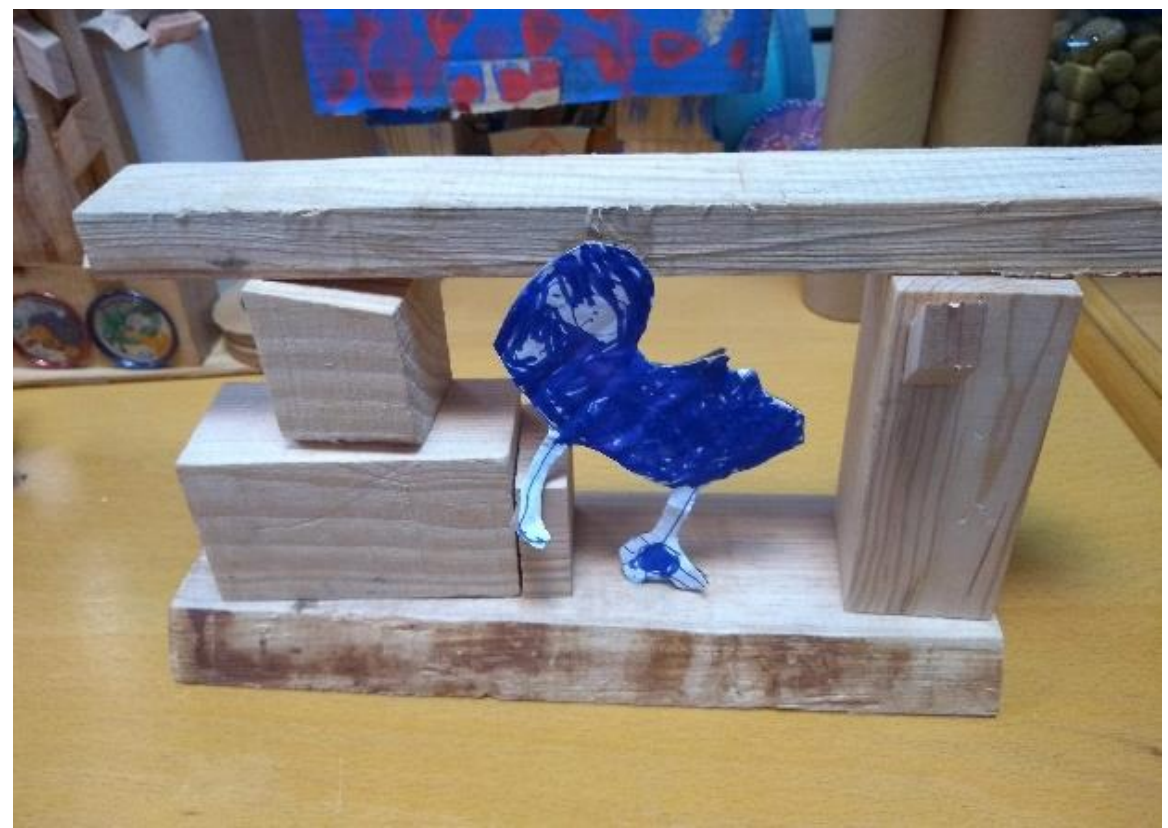

Fonte: Arquivo de Luciana Esmeralda Ostetto.

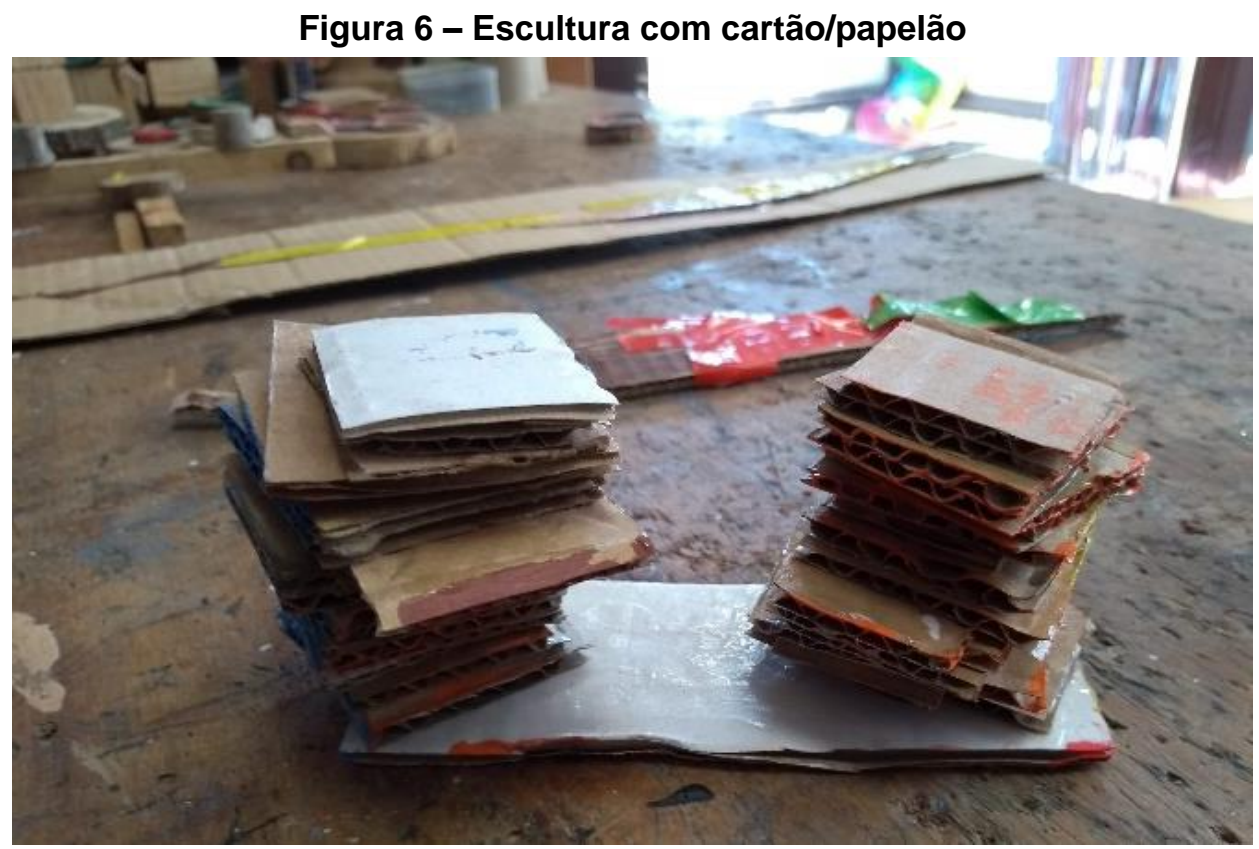

Fonte: Arquivo de Luciana Esmeralda Ostetto. 


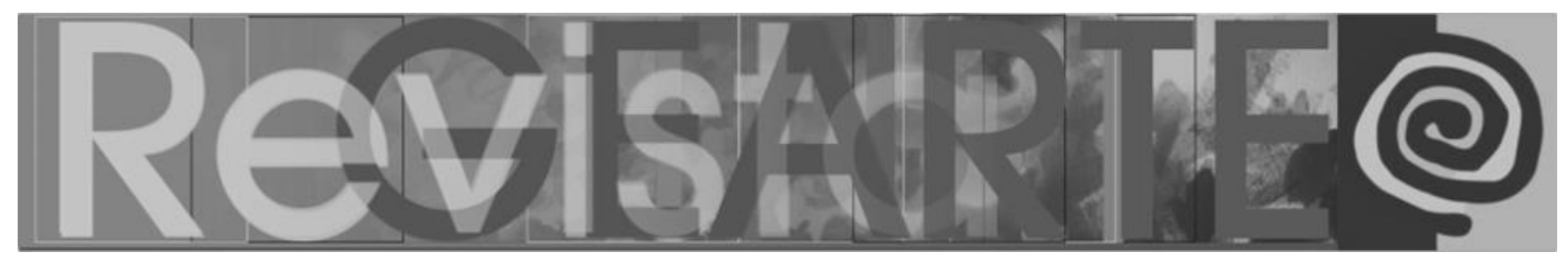

Figura 7 - Escultura com madeira

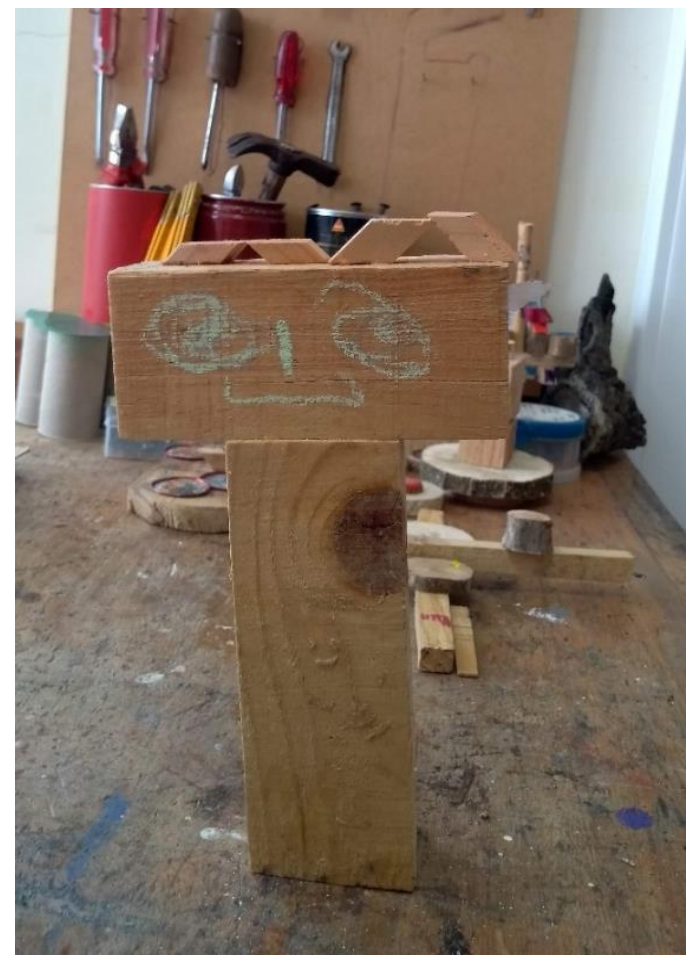

Fonte: Arquivo de Luciana Esmeralda Ostetto.

Figura 8 - Escultura com argila e galho de árvore

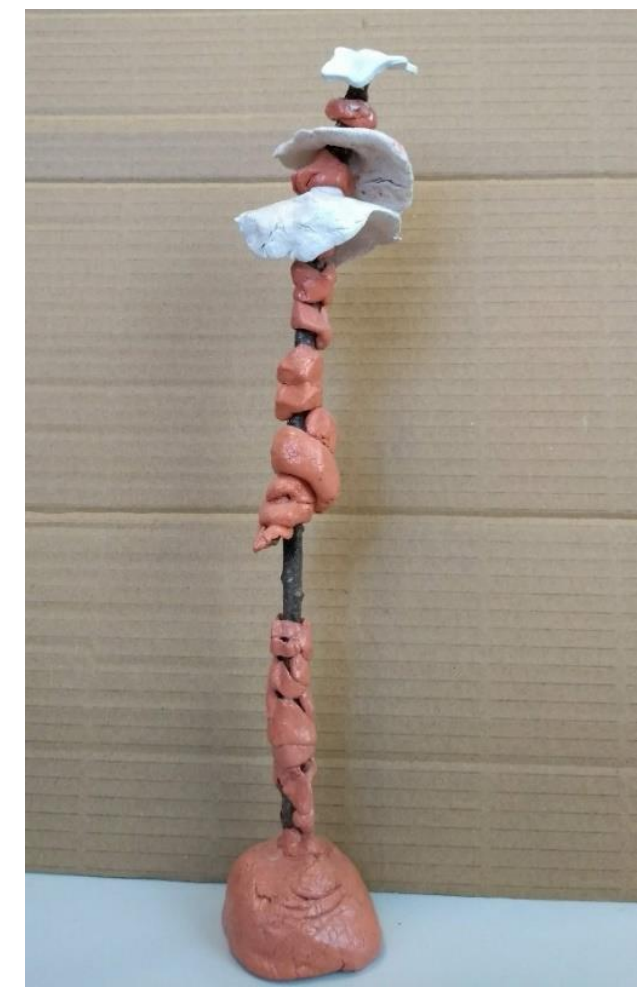

Fonte: Arquivo de Luciana Esmeralda Ostetto. 


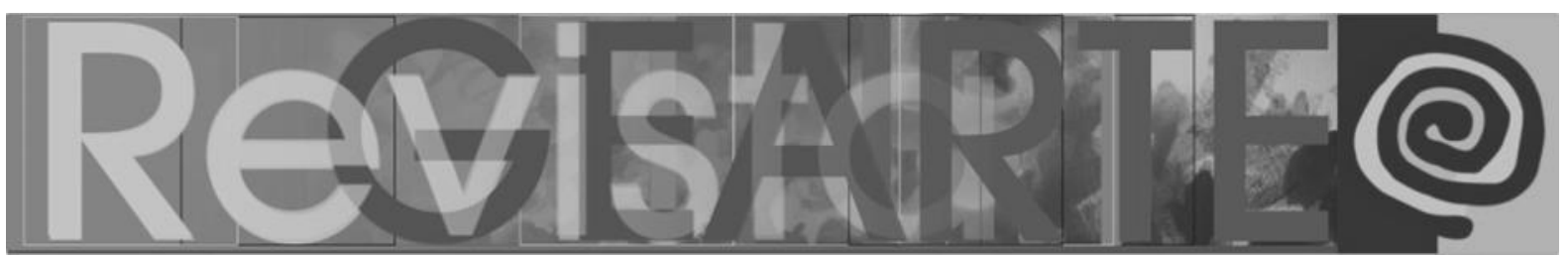

A constância na frequentação de espaços museais é que trará a intimidade e possibilitará experiências e conhecimento, não uma visita esporádica e pontual, com o objetivo marcado de fazer isso ou aquilo, de ver essa ou aquela obra, porque tem relação com aquele tema que está sendo desenvolvido.

\section{Das artes visuais à nutrição cultural: afirmar o papel da educação}

Para finalizar o roteiro de reflexão proposto, relembramos que as linguagens visuais, como todas as outras linguagens, estão presentes e são utilizadas no cotidiano das crianças, assim como de qualquer pessoa. Mas podem se desenvolver quando são nutridas por contextos culturais favoráveis e, nesse sentido, as instituições de Educação Infantil ou de outros níveis de ensino, cumprem um papel decisivo de mediação artístico-cultural.

A formação estética, que passa pela ampliação de repertórios artísticos, potencialização e refinamento das linguagens expressivas na infância, precisa ser assumida pelas instituições educacionais formais. Concordamos com a pesquisadora:

[...] ninguém cria do nada. Toda criação é fruto da reorganização de elementos já existentes em seu repertório, porém de maneira inaugural, nova. Quanto maior o acervo, mais elementos de base para a criação. Todo processo de criação é, em última análise, um movimento de (re)criação. (LEITE, 2008, p. 70).

\section{Referências}

BURTON, Judith. Preâmbulo. In: CABRAL, Marta. As coisas partidas podem ser bonitas. Lisboa: APEI, 2016. p. VI.

CABRAL, Marta. As coisas partidas podem ser bonitas. Lisboa: APEI, 2016.

CUNHA, Susana Rangel Vieira da. Um pouco além das decorações das salas de aula. Reflexão e Ação, Santa Cruz do Sul, v. 13, №. 1, p. 133-149, jan./jun., 2005.

GANDINI, Leila. Espaços educacionais e de envolvimento pessoal. In: EDWARDS, Carolyn et al. As cem linguagens da criança: a abordagem de Reggio Emilia na educação da primeira infância. Porto Alegre:Artes Médicas, 1999. p.145-158.

GANZER, Adriana A. Turbilhão de sentimentos e imaginações: as crianças vão ao museu, ou ao castelo... In: LEITE, Maria Isabel; OSTETTO, Luciana E. (Orgs). Museu, educação e cultura: encontros de crianças e professores com a arte. Campinas-SP: Papirus, 2005. p.85-92.

HOLM, Anna Marie. A energia criativa natural. Pro-Posições, Faculdade de Educação / UNICAMP, v. 15, n. 1 (43), jan./abr. 2004. 


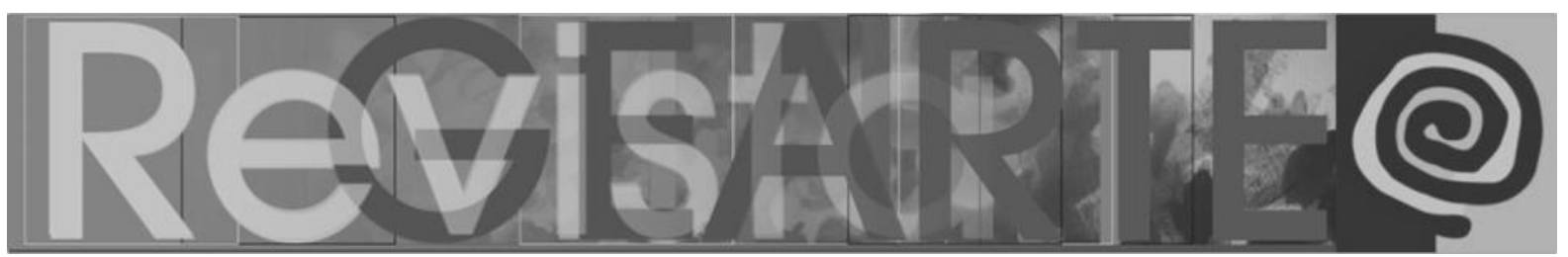

HOLM, Anna Marie. Baby-art: os primeiros passos com a arte. São Paulo: MAM, 2007.

LEITE, Maria Isabel. Museus de arte: espaços de educação e cultura. In: LEITE, Maria Isabel; OSTETTO, Luciana E. (Orgs). Museu, educação e cultura: encontros de crianças e professores com a arte. Campinas-SP: Papirus, 2005. p.19-54.

LEITE, Maria Isabel. Experiência estética e formação cultural: rediscutindo o papel da cidade e de seus equipamentos culturais. In: MAKOWIECKY, Sandra; OLIVEIRA, Sandra Regina Ramalho e (Orgs.). Ensaios em torno da arte. Chapecó: Argos, 2008. p.55-74.

MELO, Maria Isabel. Arte na Educação Infantil: histórias e práticas. Entrevista à Luciana Esmeralda OSTETTO. Évora, 15 de março de 2019 (não publicada).

OSTETTO, Luciana E. Educação infantil e arte: sentidos e práticas possíveis. Cadernos de Formação da UNIVESP. São Paulo: Cultura Acadêmica. 2011. p. 27-39. Disponível em: <http://www.acer vodigital.unesp.br/bitstream/123456789/320/1/01d14t01.pdf> Acesso em:

RINALDI, Carla. O ambiente da infância. In: CEPPI, Giulio; ZINI, Michele. (Orgs). Crianças, espaços, relações: como projetar ambientes para a educação infantil. Porto Alegre: Penso, 2013. p.122-128.

VECCHI, Vea. I linguaggi poetici come contrapposizione alla violenza. In: REGGIO CHILDREN. Bambini arte artisti. Reggio Emilia: Reggio Children, 2007. p.137-143.

VECCHI, Vea. Arte y creatividad en Reggio Emilia; el papel de los talleres y sus posibilidades en educación infantil. Madrid: Ediciones Morata, 2013.

\section{Luciana Esmeralda Ostetto}

Professora da Faculdade de Educação - Universidade Federal Fluminense, atua na pós-graduação (Mestrado e Doutorado em Educação) e na graduação (curso de Pedagogia). Foi professora do Centro de Educação - Universidade Federal de Santa Catarina (1995-2012). Possui doutorado em Educação pela Universidade Estadual de Campinas (2006), mestrado em Educação pela Universidade Federal de São Carlos (1992) e graduação em Pedagogia pela Universidade Federal de Santa Catarina (1985). Articula ensino, pesquisa e extensão na área de Educação, com ênfase em Educação Infantil e Formação de professores, contemplando principalmente os seguintes temas: educação infantil e prática pedagógica, arte e infância, arte e formação de professores, narrativas autobiográficas. Coordenadora do FIAR - Círculo de estudos e pesquisa formação de professores, infância e arte (Faculdade de Educação UFF).

ORCID: https://orcid.org/0000-0002-1948-5090

E-mail: luesmeralda@hotmail.com

Currículo: http://lattes.cnpq.br/7470127128501920

\section{Maria Isabel Melo}

Licenciatura em Educação de Infância em 1980, CESE em Supervisão Pedagógica em 2000. Exerceu funções durante 10 anos nos serviços regionais do Ministério da Educação de Portugal. Coordenadora da equipa de Intervenção Precoce de Viana do Alentejo. Fez parte da direção da APEI - Associação de Profissionais da Infância, em Portugal.

E-mail: isabelmelo@ebim.pt

Recebido em 30 de abril de 2019 Aceito em 20 de setembro de 2019 